\title{
CITED2 Mutation and methylation in children with congenital heart disease
}

\author{
Min $\mathrm{Xu}^{1,3}$, Xiaoyun $\mathrm{Wu}^{1 *}$, Yonggang $\mathrm{Li}^{2}$, Xiaofei Yang ${ }^{1,3}$, Jihua $\mathrm{Hu}^{1,3}$, Min Zheng ${ }^{1,3}$ and Jie Tian ${ }^{1}$
}

\begin{abstract}
Background: The occurrence of Congenital Heart Disease (CHD) is resulted from either genetic or environmental factors or the both. The CITED2 gene deletion or mutation is associated with the development of cardiac malformations. In this study, we have investigated the role of CITED2 gene mutation and methylation in the development of Congenital Heart Disease in pediatric patients in China.

Results: We have screened 120 pediatric patients with congenital heart disease. Among these patients, 4 cases were detected to carry various CITED2 gene heterozygous mutations (c.550G > A, c.574A > G, c.573-578del6) leading correspondingly to the alterations of amino acid sequences in Gly184Ser, Ser192Gly, and Ser192fs, respectively. No CITED2 gene mutations were detected in the control group. At the same time, we found that CITED2 mutations could inhibit TFAP2C expression. In addition, we have demonstrated that abnormal CITED2 gene methylation was detected in most of the tested pediatric patients with CHD, which leads to a decrease of CITED2 transcription activities.
\end{abstract}

Conclusions: Our study suggests that CITED2 gene mutations and methylation may play an important role in the development of pediatric congenital heart disease.

Keywords: CITED2, Mutation, Methylation, Congenital heart disease

\section{Background}

Congenital Heart Disease (CHD) is the most common disease in children with congenital birth defects, which is a challenge in pediatric cardiology. A body of studies has demonstrated that the congenital heart diseases are caused by either genetic or environmental factors or both. More and more gene mutations were found to be associated with CHD, such as NKX2.5, TBX5, TFAP2B, GATA-4 [1,2]. Although gene mutations are potential causes for the development of CHD [3], various environmental factors that affect mother during the pregnancy also play an important role in promoting and developing of CHD [4]. For example, epigenetic modifications and gene methylation changes in fetus during pregnancy can affect gene expression levels during the development [5-7]. Aberrant methylation in the promoter region of genes can inhibit gene transcription activities by preventing the binding of transcription factor from the

\footnotetext{
* Correspondence: chongwxy@aliyun.com

'Department of Cardiology, Children's Hospital of Chongqing Medical University, 136 Zhongshan Er Road, Chongqing 400014, P.R. China Full list of author information is available at the end of the article
}

target genes, which is one of the potential causes of gene silence and disease [8].

CREB-binding protein (CBP)/P300-interacting transactivator 2 is a protein with ED-rich tail that in human is encoded by the CITED2 gene. CITED2 expression is regulated by a variety of factors such as hypoxia, cytokines, oxidative stress, etc. [9]. There are a plurality of transcription factor binding sites in the promoter region of CITED2 gene, such as HIF-1, AP-2, SP1 etc., which play a vital role in CITED2 expression. Three consecutive sequence of "ACGTG" in CITED2 promoter region can maintain the stability of the combination between CITED2 and HIF-1 [10,11]. HIF-1 consists of $\alpha, \beta$ two subtypes, in which HIF- $1 \alpha$ is degraded under normal oxygen conditions and cannot be detected. However, HIF$1 \alpha$ can be detected in hypoxic conditions [12]. CITED2 blockes HIF- $1 \alpha$ transcriptional activity by competitively inhibiting the interaction between HIF- $1 \alpha$ and CBP/P300, Dysfunction of HIF- $1 \alpha$ in $C I T E D 2^{-/-}$mice may cause the cardiac malformation $[13,14]$. CITED2 also functions as a transcriptional co-activator by recruiting the combination of CBP/P300 and TFAP2. Deficiencies in TFAP2 co- 
activation have been suggested to cause laterality defect in $\mathrm{CITED2}^{-1-}$ mice [15].

CITED2 gene mutation was first reported by Sperling et al. in congenital heart disease [16] and the mutation could significantly diminish TFAP2c co-activation. However, the relationship between CITED2 mutations and $\mathrm{CHD}$ as well as the epigenetic modification of the gene is not clear. In the present study, we have screened 120 pediatric patients with $\mathrm{CHD}$ and tried to reveal the role of gene mutations and epigenetic modifications in the development of CHD in children. Our study suggests that CITED2 gene mutations and methylation may play an important role in the development of pediatric congenital heart disease.

\section{Methods}

\section{Subjects}

Blood samples were obtained from 120 pediatric patients (from 8 days to 18 years) and from 100 normal children with matched age. In addition, myocardial tissues were collected from 31 pediatric patients with CHD in Children's Hospital of Chongqing Medical University and 2 normal cardiac tissue samples were obtained from children died of accident (Table 1). The protocols and assays of the study was approved by the Ethics Committee in Children's Hospital Chongqing Medical University before the start of the study.

\begin{tabular}{lll}
$\begin{array}{l}\text { Table } \mathbf{1} \text { Phenotypies and clinical manifestations of CHD } \\
\text { in pediatric patients }\end{array}$ & $\mathbf{n}(\mathbf{\%})$ & $\mathbf{( n = 1 5 1 )}$ \\
\hline Congenital heart disease & 1 & $(0.67)$ \\
\hline Right Atrial Isomerism & 1 & $(0.67)$ \\
Single Atrium & 2 & $(1.3)$ \\
Dextral Heart & 2 & $(1.3)$ \\
Aortic Stenosis & 2 & $(1.3)$ \\
Aortic Transection & 2 & $(1.3)$ \\
Mirror Dextrocardia & 11 & $(7.28)$ \\
Atrial Septal Defect with Ventricular Septal Defect & 3 & $(2.0)$ \\
Persistent Truncus Arteriosus & 4 & $(2.65)$ \\
Complete Transposition of Great Arteries & 4 & $(2.65)$ \\
Pulmonary Atresia & 4 & $(2.65)$ \\
Total Anomalous Pulmonary Venous Drainage & 5 & $(3.31)$ \\
Single Ventricle & 8 & $(5.3)$ \\
Pulmonary Stenosis & 10 & $(6.62)$ \\
Double Outlet Right Ventricle & 24 & $(15.9)$ \\
Atrial Septal Defect & 20 & $(13.2)$ \\
Patent Ductus Arteriosus & 33 & $(21.9)$ \\
Ventricular Septal Defect & 13 & $(8.61)$ \\
Tetralogy of Fallot & 2 & $(1.3)$ \\
Complete Atrioventricular Pathways & &
\end{tabular}

\section{Reagents}

Blood and Tissue DNA extraction kit was purchased from Tiangen; plasmid pEGFP-C1 was purchased from Dingguo biotechnology company; LA Tag enzyme, pMD19-T simple plasmid restriction enzyme ScaI and KpnI, DNA ligase, DNA marker, Reverse transcription kits were purchased from TaKaRa; Endotoxin-free plasmid extraction kit was purchased from QIAGEN; DMEM medium, fetal bovine serum were purchased from Gibco; Lipofectamine TM 2000 was purchased from Invitrogen;SsoFastTM EvaGreen Supermix was purchased from BIO-RAD, TFAP2c primary antibody, HIF- $1 \alpha$, anti- $\beta$-action antibody were purchased from Bioworld;EZ DNA MethylationGold Kit, methylation positive control and a negative control were purchased from ZYMO;HepG2 and H9C2 cell were conserved in our laboratory.

\section{Detection of mutations in CITED2 gene}

Blood DNA was extracted from the CHD and healthy children. CITED2 coding region was cut into S1 and S2 to design primers. The primer sequences used in the assays are shown in Table 2. PCR amplification, and then sequencing were performed. DNA sequence was compared to the normal CITED2 coding sequence in the Genebank to reveal the mutation sites and types.

\section{Construct CITED2 mutant and wild-type recombinant plasmid}

CITED2 (c.573-578del6) and normal PCR purification products were connected with pMD19-T simple plasmid. Then they were transformed into competent E. coli $\mathrm{DH} 5 \alpha$ and the positive clones were detected. Again, the positive clones were selected and sequenced.

\section{Transfection of plasmids into the cells}

Human hepatoma cell line HepG2 and Rats myocardial cell lines H9C2 were cultured in DMEM medium containing $10 \%$ fetal bovine serum. The medium was changed regularly. Recombinant plasmids were transfected into HepG2 and H9C2 using Lipofectamine ${ }^{\mathrm{Tm}}$ 2000. The transfection efficiency of pEGFP-C1-wtCITED2 and pEGFPC1-mtCITED2 were observed by fluorescence microscopy. The expression of CITED2 was analyzed with Western blotting. Experimental groups included: Empty vector group, Untransfected group, Mutation group and Wildtype control group.

\section{Detection of TFAP2c and HIF-1a mRNA expression by Q-PCR}

After transfection, the cells were cultured in the different conditions $\left(21 \% \mathrm{O}_{2}, 74 \% \mathrm{~N}_{2}, 5 \% \mathrm{CO}_{2}\right.$ at $37^{\circ} \mathrm{C}$ or $1 \%$ $\mathrm{O}_{2}, 94 \% \mathrm{~N}_{2}, 5 \% \mathrm{CO}_{2}$ at $\left.37^{\circ} \mathrm{C}\right)$. RNA was extracted after $24 \mathrm{~h}$ and reversely transcribed into cDNA. HIF- $1 \alpha$ and TFAP2c was amplified by SsoFast ${ }^{\mathrm{Tm}}$ EvaGreen Supermix. 
Table 2 Specific primers designed for the experiments

\begin{tabular}{|c|c|c|c|}
\hline Species & Gene & Primer sequences & Amplified length \\
\hline \multirow[t]{16}{*}{ Human } & CITED2 & S1: Sense: 5'-AGGCTGTTAGTGGGATCTTGG -3' & $559 \mathrm{bp}$ \\
\hline & & Anti: 5'-CATGTAGTGGTT- GTGGGGGTAG -3' & \\
\hline & & S2: Sense: 5'-CCAGGTTTAACAACTCCCAGTTC-3' & \\
\hline & & Anti: 5'-CCACAAGATTAAGCAGTTTGCC-3' & \\
\hline & & BSP: Sense: 5'-GGTGGGGTAGATTTAGTTTGAGG-3' & $350 \mathrm{bp}$ \\
\hline & & Anti: 5'-ACTTAAACCACAATTAATATAAACA TTC -3' & \\
\hline & & MSP: MF: 5'-CGCGTGGTGTTATACGGGACG -3' & $199 \mathrm{bp}$ \\
\hline & & MR: 5'-ACAAAACCTCCCTCCGAACT -3' & \\
\hline & & UF: 5'-TGTGTGGTGTTATATGGGATG-3' & \\
\hline & & UR: 5'-ACAAAACCTCCCTCCAAACT-3' & \\
\hline & TFAP2C & Sense: 5'-AAATCCTTCTCCACCGCACAGACT-3' & $100 \mathrm{bp}$ \\
\hline & & Anti: 5'-TGATGCAGAACCAGTGAAGGCTCT-3' & \\
\hline & HIF-1a & Sense: 5'-CGTTCCTTCGATCAGTTGTC-3' & $143 \mathrm{bp}$ \\
\hline & & Anti: 5'-TCAGTGGTGGCAGTGGTAGT-3' & \\
\hline & $\beta$-actin & Sense: 5'-CATGGGTCAGAAGGATTCCTATGTG-3' & $116 \mathrm{bp}$ \\
\hline & & Anti: 5'-ATTITCTCCATGTCGTCCCAGTTG-3' & \\
\hline \multirow[t]{6}{*}{ Rats } & TFAP2C & Sense: 5'-GGATTTAACTGGCGACTAT-3' & $79 \mathrm{bp}$ \\
\hline & & Anti: 5'-CCTCTTCATACTTGACATTATC-3' & \\
\hline & HIF-1a & Sense: 5'-CTGCCACCACTGATGAAT-3' & $128 \mathrm{bp}$ \\
\hline & & Anti: 5'-ACTGTATGCTGATGCCTTAG-3' & \\
\hline & $\beta$-actin & Sense: 5'- TATGGAATCCTGTGGCATC-3' & $87 \mathrm{bp}$ \\
\hline & & Anti: 5'-GTGTTGGCATAGAGGTCTT-3' & \\
\hline
\end{tabular}

The sequences of the primers used in the assays are shown in Table 2. Expression differences of TFAP2c and HIF- $1 \alpha$ mRNA was compared among the four assay groups. Each experiment was repeated at least three times.

\section{Detection of TFAP2c and HIF-1a protein levels by Western blotting}

After transfecting, cells were respectively cultured in the condition of $37^{\circ} \mathrm{C}, 21 \% \mathrm{O}_{2}, 74 \% \mathrm{~N}_{2}, 5 \% \mathrm{CO}_{2}$ and $37^{\circ} \mathrm{C}$, $1 \% \mathrm{O}_{2}, 94 \% \mathrm{~N}_{2}, 5 \% \mathrm{CO}_{2}$. Proteins were collected after $48 \mathrm{~h}$ and boiled with buffer for $5 \mathrm{~min}$ and then separated by SDS-PAGE gel electrophoresis. Transferring protein onto PVDF and blocking $1 \mathrm{~h}$ with $5 \%$ skim milk. The membranes was incubated at $4^{\circ} \mathrm{C}$ overnight after hatching TFAP2c and HIF- $1 \alpha$ antibodies. The PVDF was washed three times in PBST. TFAP2c and HIF-1 $\alpha$ protein levels were compared among the four different groups. At least three independent experiments were performed.

\section{Detection of methylation in CITED2 gene promoter region (CpG island)}

Genomic DNA was extracted from myocardial tissues of $\mathrm{CHD}$ and control groups and treated with bisulfite modification using an EZ DNA Methylation-Gold Kit. This treatment converts unmethylated cytosines to uracils, while methylated cytosines unchanged. CITED2 $(-10 \mathrm{bp} \sim-360 \mathrm{bp})$ region was detected by Bisulfite-PCR sequencing (BSP). The methylation sites were identified after PCR amplification of the cloning and sequencing. The methylation on CITED2 (-971 bp -1171 bp) was detected using a methylation- specific PCR (MSP) assay. The methylated or unmethylated samples was analyzed by $2 \%$ agarose gel electrophoresis.

\section{Detection of CITED2 mRNA expression by Q-PCR}

RNA was extracted from the methylated and control groups and reversely transcribed into cDNA. The transcriptional expression of CITED2 gene was detected and compared. $\beta$-actin was used as an internal control.

CITED2: Sense: 5'-TTCCCTCACTTTCTCCAGTGCT CA-3 antisense: 5'-ATGAAGCGAGATGGCAGTTTGT GC-3', Length:191 bp; $\beta$-actin: Sense: 5'-CATGGGTCAG AAGGATTCCTATGTG-3' antisense: 5'-ATTTTCTCCAT GTCGTCCCAGTTG-3', length:116 bp.

\section{Statistical analysis}

Statistical analysis was performed using student's t-test or Fish's exact test and $X^{2}$ test. The obtained $\mathrm{P}$ values 
are indicated in the text. All data were analyzed with SPSS.17.0 software.

\section{Results}

\section{Mutations detected in CITED2 coding region}

4 heterozygous mutations were detected among $120 \mathrm{pa}-$ tients with congenital heart disease, Including 2 cases of point mutations and 2 cases of deletion mutants. These mutations lead to corresponding amino acid variations in CITED2 protein. However no mutation were detected in samples from the 100 normal controls (Table 3).

\section{Measurement of TFAP2c and HIF-1a mRNA expressions}

CITED2 wild-type and mutant recombinant plasmids were constructed successfully. By comparison to the wild-type plasmid pEGFP-C1-wtCITED2, the recombinant mutant plasmid pEGFP-C1-mtCITED2 could be identified by the absence of six bases based on sequencing. TFAP2c mRNA expression levels were reduced significantly in mutant group comparing to the wildtype group in $\mathrm{H} 9 \mathrm{C} 2(P<0.05)$. The empty vector group and untransfected group showed no statistical difference $(P>0.05)$. By contrast, HIF- $1 \alpha$ mRNA expression levels were higher in the mutant group than that in wild-type group $(P<0.05)$ (Figure 1A). Similarly, in HepG2 cells, we aslo found the same results, TFAP2c mRNA expression levels were reduced in mutant group comparing to the wild-type group, But HIF- $1 \alpha$ mRNA expression levels were higher in the mutant group than that in wild-type group $(P<0.05)$ ( Figure 1B).

\section{Determination of protein expression levels of TFAP2c and HIF-1a}

The concentrations of TFAP2c protein were reduced in the mutant group comparing to that of the empty vector group in $\mathrm{H} 9 \mathrm{C} 2(P<0.05)$. TFAP2c protein concentrations were significantly lower in the mutant group comparing to the wild-type control group $(P<0.05)$. The empty vector group and untransfected group showed no significant difference $(P>0.05)$. Similarly to the mRNA data, the concentrations of HIF- $1 \alpha$ protein was higher in the mutant group than that of the wild-type control group $(P<0.05)$ (Figure $1 C)$. Similarly, in HepG2 cells, It

Table 3 CITED2 gene mutations detected in pediatric patients with CHD

\begin{tabular}{llll}
\hline Nucleotide & Amino acid & Number & Phenotype \\
\hline c.550G $>$ A & p.Gly184Ser & 1 & $\begin{array}{l}\text { Mirror dextrocardia, right aortic } \\
\text { arch, tetralogy of Fallot }\end{array}$ \\
c.574A $>$ G & p.Ser192Gly & 1 & Aortic stenosis \\
c.573-578del6 & p.Ser192fs & 2 & $\begin{array}{l}\text { Aortic stenosis and pulmonary } \\
\text { valve stenosis; ventricular } \\
\text { septal defect and atrial septal } \\
\text { defect }\end{array}$ \\
\hline
\end{tabular}

shows the same results, TFAP2c protein concentrations were lower in the mutant group comparing to the wildtype control group $(P<0.05)$, but the concentrations of HIF- $1 \alpha$ protein was higher in the mutant group than that of the wild-type control group $(P<0.05)$ (Figure 1D).

\section{Detection of methylation in CITED2 promoter region}

Two methods were used to detect the methylation in gene promoter region. One was to use bisulfate-PCR primers (BSP) and the other was to use methylationspecific PCR primers (MSP). Both primers were described in Materials and Methods. The sequencing data from BSP showed that methylation was detected in 10 cases out of 12 patient samples tested (83\% of methylation positive rate). The samples from the normal control group were small with only two cases. However, no methylation was detected in the control samples (Figure 2A). The MSP showed that the methylation was detected in 16 cases out of 19 patients with CHD ( $84 \%$ of methylation-positive rate). No methylation was detected using this method in 2 normal control samples (Figure 2B). It was also found that CITED2 expression levels were significantly decreased in samples with methylation in CITED2 promoter region compared to that of the samples without methylation in CITED2 $(\mathrm{P}<0.05)$ (Figure 3$)$.

\section{Discussion}

CITED2 gene is one important member of the CITED family. It is located in chromosome 6q23.3 and contains three exons and two introns, encoding a protein with 270 amino acids. The amino acid sequence of CITED2 protein is characterized by three conserved regions (CR1, CR2 and CR3). CR2 is a conserved region consisting of 32 amino acids, which binds with $\mathrm{CH} 1$ domain of $\mathrm{CBP} / \mathrm{P} 300$. A unique serine-glycine-rich region (SGJ) is located in its carboxyl terminus. CITED2 gene has about $3 \mathrm{~kb}$ of $\mathrm{CpG}$ islands in its promoter region and coding region that may be modified by methylation [10]. In this study we have detected 4 various mutations in CITED2 coding region (c.550G > A, c.574A > G, c.573-578del6) in blood samples from pediatric patients with CHD. All of these mutations are clustered in the SGJ area. The different mutations are associated with different phenotypes of $\mathrm{CHD}$ in pediatric patients, and a same mutation causes different CHD phenotypes. So gene mutation along can not well explain the occurrence of CHD, suggesting that other factors play roles in the development of CHD. In this study, we have demonstrated that methylation levels of certain important genes, such as CITED2, are associated as well with the development of the CHD.

Previous studies have shown that CITED2 plays an important role in the heart development. Lack of CITED2 


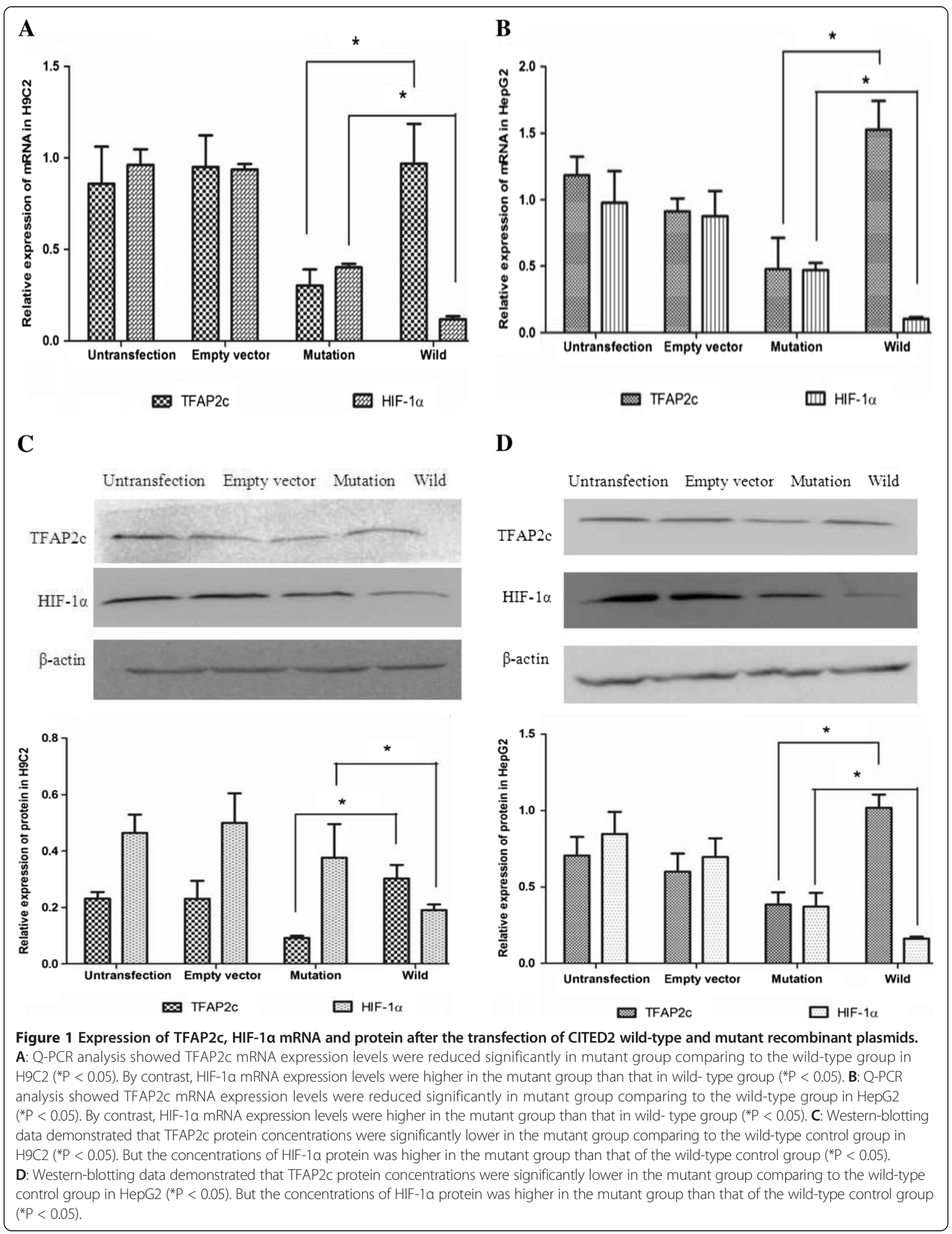



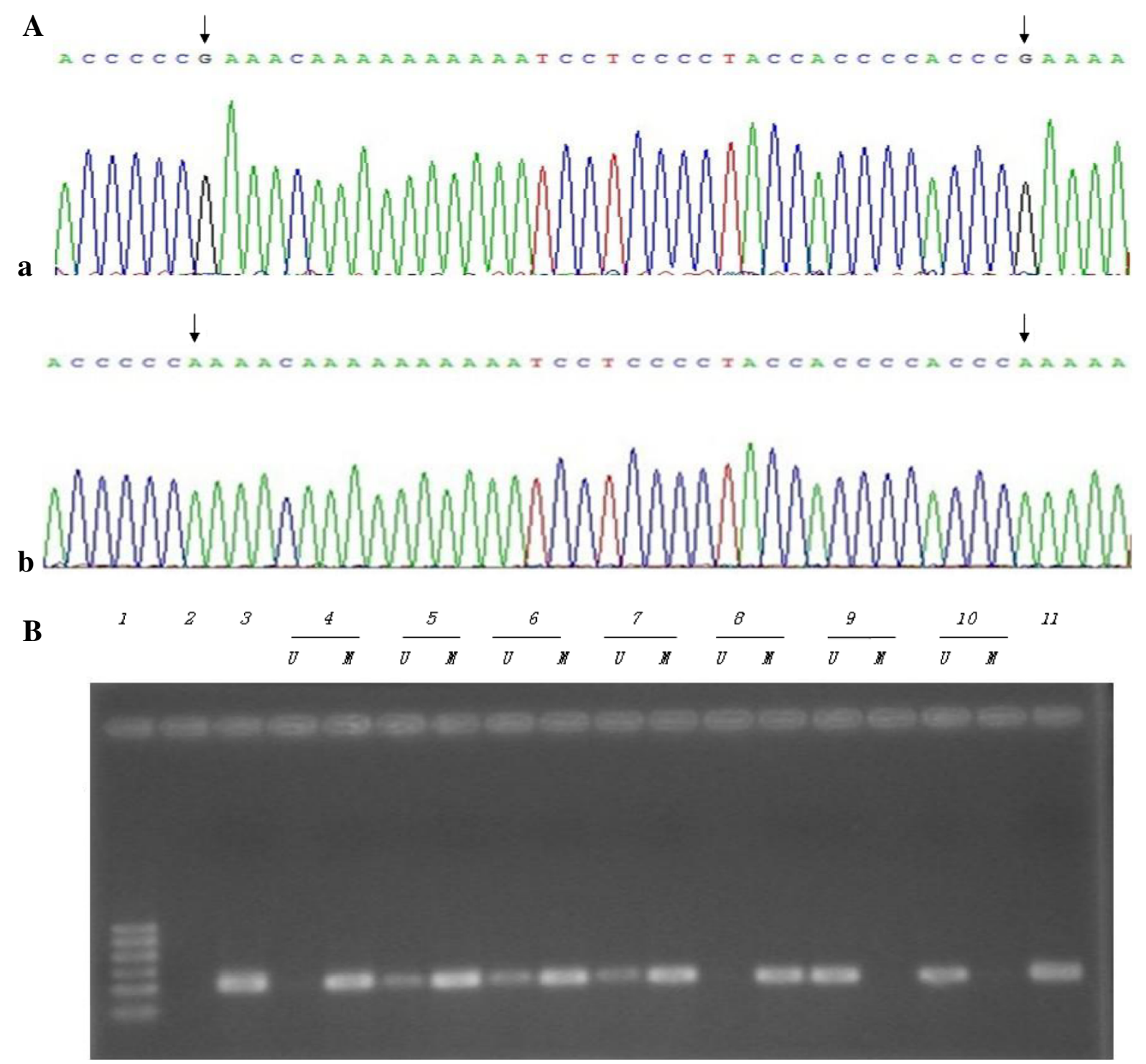

Figure 2 The clone sequencing and Electrophoresis by BSP and MSP. A. The clone sequencing of reverse complementary chain in CHD and control group by BSP. a: It shows the methylated sequence in CHD group, arrow represent methylated sites; $\mathbf{b}$ : The corresponding non-methylated sequences in control group, arrow represent unmethylated sites. B. It shows the result of Electrophoresis by MSP. it demonstrates that Methylated strip exsits in the samples with CHD,but in the control group it shows the Unmethylated strip. It demonstrates that CITED2 methylation exsits in CHD group. 1: DNA Marker 100-600 bp, 2: Blank control (ddH2O), 3: Methylated positive control, 11: Negative control, 4-8: Methylated samples in congenital heart disease, 9-10: Unmethylated samples in the control group, M: methylated strip, U: unmethylated strip.

in embryos can cause an abnormal heart ring formation, as well as various cardiac malformations including artial and ventricular septal defects, transposition of great arteries, double outlet right ventricle, tetralogy of fallot and so on [17]. Heart-specific knockout of CITED2 in mice leads to a ventricular septal defect and ventricular wall thinning, as well as abnormal angiogenesis, suggesting that CITED2 plays a vital role in the growth and development of ventricular muscles and ventricular septal coronary vessels [18]. CITED2 can act as a transcription cofactor assisting various transcription factors to modulate a normal development of the heart. CITED2-/- embryos can down-regulate Nodal, Lefty2 and Pitx2 expression in the left side plate mesoderm, which hampers the formation of the normal axis of the mouse heart [19]. CITED2 and HIF- $1 \alpha$ can competitively bind on $\mathrm{CH} 1$ domain of CBP/P300. So CITED2 has been proposed to be a negative-feedbacked inhibitor under a hypoxic environment to limit HIF- $1 \alpha$ overexpression. This negative feedback action is diminished when CITED2 gene is deleted or downregulated, which leads to an overexpression of HIF$1 \alpha$ [20-23]. Our study has further confirmed that CITED2 


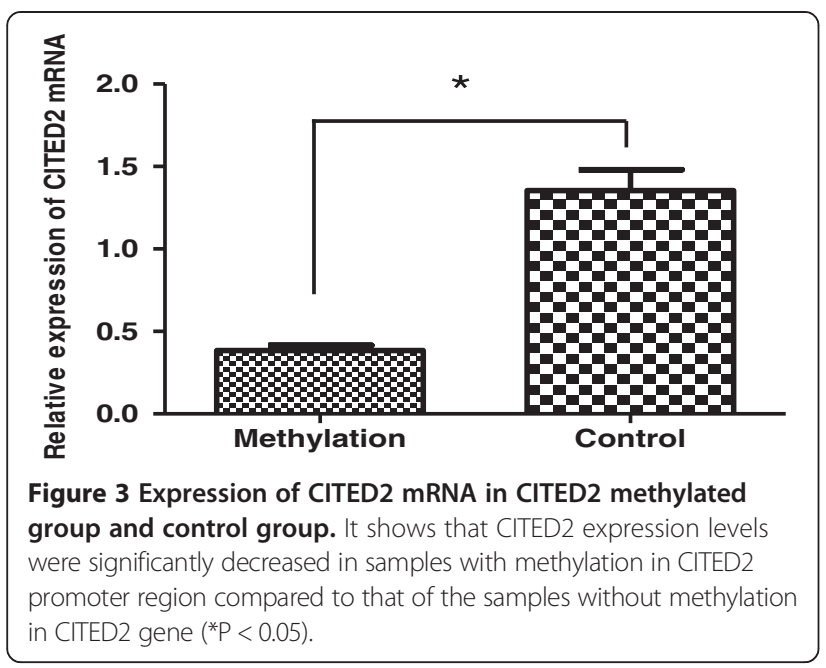

can, indeed, inhibit HIF- $1 \alpha$ expression since this inhibition is diminished by CITED2 mutations detected in pediatric patients with CHD. As a consequence, the HIF- $1 \alpha$ expression is enhanced in pediatric CHD patients with CITED2 mutations. The overexpression of HIF- $1 \alpha$ might bring the following events that are associated with the development of CHD: 1) HIF- $1 \alpha$ can suppress cell apoptosis in cardiac outflow tract. Cell apoptosis will be inhibited because of HIF- $1 \alpha$ overexpression, which hinders the development of cardiac outflow tract. 2) HIF-1 $\alpha$ overexpression can increase the expression of its target gene VEGF, which blocks the development of vasculature and leads to myocardial ischemia and hypoxia. 3) HIF-1 $\alpha$ overexpression inhibits migration and transition of neural crest cell, which hinders the formation of a normal heart.

The CR3 binding domain of CITED2 can bind with TFAP2, and its CR2 binding domain can bind CBP/ P300, So CITED2 as a bridge between TFAP2 and CBP/ P300 can activate the transcription activity of TFAP2. Lower TFAP2 transcriptional activity in CITED2-/mice confirmed this view [24]. TFAP2c and TFAP2a can interact with CITED2, especially TFAP2c [25]. In our study the connection between TFAP2c and CBP/P300 weaked owing to CITED2 mutation, so there is a reduction in TFAP2c. Abnomal expression of TFAP2c can limit the development of cardiac neural rest. TFAP2c low expression further affect transcriptional regulator Pitx2 expression, which hamper the formation of the normal axis of the heart.

Methylation is a process that transfers $-\mathrm{CH} 3$ to the specific base. Gene methylation plays a critical role in cell proliferation, differentiation and apoptosis. Aberrant methylation was mainly induced by environmental factors. And the incidence of congenital heart disease is closely associated with environmental factors during the pregnancy. Various factors during the pregnancy, such as ethanol, riboflavin and folic acid, can induce gene methylations in vivo [26-30]. Studies have shown that maternal high-fat diet combined with CITED2 gene deletion can increase penetrance of the heart abnormality body axis [31]. A close correlation has been discovered between congenital heart disease with the CITED2 gene deletion and environmental alteration. Zhu et al. reported that several abnormally methylated bases were found in ventricular septal defects and NOX5 hypermethylation in CpG island can inhibit its expression [32]. Our study confirms that methylation of CITED2 gene promoter region is observed in pediatric patients with CHD and the methylation can decrease CITED2 transcription activity.

\section{Conclusions}

In conclusion, our study discovers the CITED2 gene mutations as well as CITED2 gene promoter region methylation in pediatric patients with $\mathrm{CHD}$, which affects transcriptional activity of TFAP2c and HIF- $1 \alpha$. The latter are closely associated with the heart development. Our data suggest that both gene mutations and epigenetic modifications play a role in the development of CHD.

\section{Consent}

Written informed consent was obtained from the patient for the publication of this report and any accompanying images.

\section{Competing interests}

The authors declare that they have no competing interests.

\section{Authors' contributions}

$X Y W, J T, X F Y$ and JHH designed research planning. YGL participated in the patient data collection. MX, XFY, JHH and $M Z$ performed the experiments. $X Y W, M X, X F Y, J H H$ and $M Z$ analyzed the data and writing the manuscript. $X Y W$ was a responsible author and gave final approval of the version to be published. All authors read and approved the final manuscript.

\section{Acknowledgements}

The authors thank Prof. Xupei Huang from the Florida Atlantic University, USA, for his critical reading and editing of the manuscript. This work was supported by Health Medicine Research Project of Chongqing Health Inspection Bureau (2009-2-259), Natural Science Foundation of Chongqing Science and Technology Commission (C2008BB5071), Start-up Project for Returnee of Ministry of Human Resources and Security of China [(2009)116], and Science Foundation of Chongqing YuZhong District (2012).

\section{Author details}

${ }^{1}$ Department of Cardiology, Children's Hospital of Chongqing Medical University, 136 Zhongshan Er Road, Chongqing 400014, P.R. China.

${ }^{2}$ Department of Cardio-thoracic surgery, Children's Hospital of Chongqing Medical University, Chongqing 400014, P.R. China. ${ }^{3}$ Ministry of Education Key Laboratory of Child Development and Disorders, Key Laboratory of Pediatrics in Chongqing, CSTC2009CA5002, Chongqing International Science and Technology Cooperation Center for Child Development and Disorders, Chongqing, P.R. China.

Received: 1 November 2013 Accepted: 20 January 2014

Published: 24 January 2014 


\section{References}

1. Kodo K, Nishizawa T, Furutani M, et al: Genetic analysis of essential cardiac transcription factors in 256 patients with non-syndromic. Circ J 2012, 76(7):1703-1711.

2. Xiong F, Li Q, Zhang C, et al: Analyses of GATA4, NKX2.5, and TFAP2B genes in subjects from southern China with sporadic congenital heart disease. Cardiovasc Pathol 2012, 22(2):141-145.

3. Blue GM, Kirk EP, Sholler GF, et al: Congenital heart disease: current knowledge about causes and Inheritance. Med J Aust 2012, 197(3):155-159.

4. Crider KS, Bailey LB: Defying birth defects through diet? Crider and Bailey Genome Medicine 2011, 3:9.

5. Chowdhury S, Erickson SW, Macleod SL, et al: Maternal genome-wide DNA methylation patterns and congenital heart defects. PLOS One 2011, 6(1):1-11.

6. Liang P, Song F, Ghosh F, et al: Genome-wide survey reveals dynamic widespread tissue-specific changes in DNA methylation during development. BMC Genomics 2011, 12:231-247.

7. Zhu C, Yu XB, Chen BH, et al: Screening for differential methylation status in fetal myocardial tissue samples with ventricular septal defects by promoter methylation microarrays. Mol Med Rep 2011, 4:137-143.

8. Yang $M, L i W$, Liu YY, et al: Promoter hypermethylation-induced transcriptional down-regulation of the geneMYCT1 in laryngeal squamous cell carcinoma. BMC Cancer 2012, 12:219-238

9. MacDonald ST, Bamforth SD, Braganc J, et al: A cell-autonomous role of Cited2 in controlling myocardial and coronary vascular development. European Heart Journal Advance Access 2012, 14:1-9.

10. Leung MK, Jones $\mathrm{T}$, Michels $\mathrm{CL}$, et al: Molecular cloning and chromosomal localization ofthe human CITED2 gene encoding p35srj/Mrg1. Genomics 1999, 61(3):307-313.

11. Han BG, Liu N, Yang XM, et al: MRG1 Expression in fibroblasts is regulated by Sp1/Sp3 and an Ets transcription factor. J Biol Chem 2001, 276:7937-7942.

12. Gobble RM, Groesc KA, Chang M, et al: Differential regulation of human PIGF gene expression inTrophoblast and nontrophoblast cells by oxygen tension. Placenta 2009, 30(10):869-875.

13. Yin Z, Haynie J, Yang XM, et al: The essential role of Cited2, a negative regulator for HIF-1 in heart in development and neurulation. Proc Nat Acad Sci USA 2002, 99(16):10488-10493.

14. Du J, Yang YC: HIF-1 and its antagonist Cited2. Cell Cycle 2012, 11(13):1-2.

15. Bamforth SD, Braganca J, Eloranta JJ, et al: Cardiacmalformations, adrenalagenesis, neural crest defects and exencephaly in mice lacking Cited2, a new Tfap2 co-activator. Nat Genet 2001, 29:469-474

16. Sperling S, Grimm C, Dunkel I, et al: Identification and functional analysis of CITED2 mutations in patients with congenital heart defects. Hum Mutat 2005, 26(6):575-582.

17. MacDonald ST, Bamforth SD, Chen M: Epiblastic Cited2 deficiency resultsin cardiac phenotypic heterogeneity and provides a mechanism for haploinsufficiency. Cardiovasc Res 2008, 79:448-457.

18. Simon T, MacDonald, Simon D: A cell-autonomous role of Cited2 in controlling myocardial andcoronary vascular development. Eur Heart J 2012, 4:1-9.

19. Weninger WJ, Floro KL, Bennett MB, et al: Cited2is required both for heart morphogenesis and Establishment of the left-right axis in mouse development. Development 2005, 132(6):1337-1348.

20. Bhattacherjee $\mathrm{V}$, Hong $\mathrm{KH}$, Singh S, et al: $\mathrm{CBP} / \mathrm{p} 300$ and associated transcriptional co-activators exhibit distinct Expression patterns during murine craniofacial and neural tube development[J]. Int J Dev Biol 2009, 53(7):1097-1104

21. Lee JY, Taub PJ, Wang L, et al: Identification of CITED2 as a negative regulator of fracture healing. Biochem Biophys Res Commun 2009, 387(4):641-645.

22. Agrawal A, Gajghate S, Smith H, et al: Cited2 Modulates hypoxia-inducible factor-dependent expression of vascular endothelial growth factor in nucleus pulposus cells of the rat intervertebral disc. Arthritis Rheum 2008, 58(12):3798-3808.

23. Amati $F$, Diano $L$, Campagnolo $L$, et al: Hif1a down-regulation is associated with transposition of great arteries in mice treated with a retinoic acid antagonist. BMC Genomics 2010, 11:497.

24. Braganca J, Eloranta JJ, Bamforth SD, et al: Physical and functional interactions among AP-2 transcription factors, p300/CREB-binding protein, and CITED2. J Biol Chem 2003, 278(18):16021-16029.
25. Li W, Cornell CR: Redundant activities of Tfap2a and Tfap2c are required for neural crest induction and development of other non-neural ectoderm derivatives in zebrafish embryos. Dev Biol 2007, 304(1):338-354.

26. Zhou FC, Zhao Q, Liu YL, et al: Alteration of gene expression by alcohol exposure at early neurulation. BMC Genomics 2011, 12:124-141.

27. Philibert RA, Plume JM, Gibbons FX, et al: The impact of recent alcohol use on genome wide DNA Methylation signatures. Fronters in genetics 2012, 3:54-61.

28. Lawrence J, Chen M, Xiong F, et al: Foetal nicotine exposure causes PKC1 gene repression by promoter methylation in rat hearts. Cardiovasc Res 2011, 1:89-97.

29. Chan J, Deng L, Mikael LG, et al: Low dietary choline and low dietary riboflavin during pregnancy influence reproductive outcomes and heart development in mice. Am J Clin Nutr 2010, 9(4):1035-1043

30. Slater-Jefferies $\mathrm{JL}$, Lillycrop KA, Townsend PA, et al: Feeding a proteinrestricted diet during pregnan inducesaltered epigenetic regulation of peroxisomal proliferator-activated receptor- $a$ in the heart of the offspring. Journal of Developmental Origins of Health and Disease 2011, 2(4):250-255.

31. Bentham J, Michel AC, Lockstone $H$, et al: Maternal high-fat diet interacts with embryonic Cited2 genotype to reduce Pitx2c expression and enhance penetrance of left-right patterning defects. Hum Mol Genet 2010, 19(17):3394-3401.

32. Zhu C, Yuz B, Chen XH, et al: DNA hypermethylation of the NOX5 gene in fetal ventricularseptal defect. Experimental and Therapeutic Medicine 2011, 2(5):1011-1015.

doi:10.1186/1423-0127-21-7

Cite this article as: Xu et al: CITED2 Mutation and methylation in children with congenital heart disease. Journal of Biomedical Science 2014 21:7.

\section{Submit your next manuscript to BioMed Central and take full advantage of:}

- Convenient online submission

- Thorough peer review

- No space constraints or color figure charges

- Immediate publication on acceptance

- Inclusion in PubMed, CAS, Scopus and Google Scholar

- Research which is freely available for redistribution 